\title{
Editorial
}

\section{LEPROSY REVIEW: ORIGIN, POLICY, CONTENT, CIRCULATION, FINANCES AND THE FUTURE}

\section{Origin and purpose}

The Journal began life in 1928 as Leprosy Notes, a quarterly distillation of the findings of leprosy workers around the world, which was distributed to others in need of up-to-date information. Although less publicised as a contribution to the well-being of those with leprosy, Leprosy Notes and what was made of the publication is incalculable, and may still be fairly regarded as one of LEPRA's major steps towards the achievements of its aims. In 1930, under the Editorship of Dr. Robert Cochrane, an eminent leprologist who was LEPRA's (then called BELRA) first Medical and General Secretary, Leprosy Notes was re-named Leprosy Review and transformed into a high-quality medical Journal.

Leprosy Review is now a leading journal in its field, and is catalogued in several places including Index Medicus, Current Contents and the Science Citation Index to name but three. Leprosy Review had impact factors of 0.447 in 1996 and 0.607 in 1997 (data from the Journal Citation Reports database).

\section{Editorial policy and content}

The Journal has an average of 96 pages per issue. As well as original and special articles, the Journal contains The Editor's Choice, at least one Editorial, and one or more Review Articles. Letters to the Editor, Case Reports, Book Reviews and Obituaries of those concerned with leprosy are also included. Leprosy Review also prides itself on providing information to its readers on Teaching Materials and Services to which they might otherwise not have access, and also for its wide-ranging News and Notes section which enables readers to catch up on what else is going on in and around the world of leprosy. An index is included as an integral part of Issue 4 each year.

The Journal is published with the main objective of contributing towards the better understanding of leprosy and its control, and therefore is open to any manuscript dealing with leprosy or related subjects. Papers are submitted from all over the world and cover every aspect of leprosy, including research. In addition, considerable emphasis is given to material of education value which is of direct benefit and relevance to the practical aspects of the 
control of leprosy under field conditions, and therefore to the individual patient. Naturally the subject matter of any individual issue is dependent on the manuscripts accepted for publication at that time.

Leprosy Review has, since 1996, provided a free poster on an aspect of leprosy of interest to many people. Those published so far have been on Reversal (Type I) Reactions, ENL (Type II) Reactions, Immunology, Prevention of Disability, Making Slit Skin Smears, Examining Slit Skin Smears, Eye Examination, and Care of Microscopes. An evaluation of these posters was undertaken by way of a questionnaire after the first four had been distributed. An overwhelming majority of subscribers responded and judged them to be an excellent aid to their work, although of course there were minor quibbles where an African audience didn't like Asian photographs (and vice versa) but on the whole they have been a great success. So much so in fact, that over 10,000 additional posters were sent out on request, and following the ILA Congress in Beijing a further 13,800 copies of the posters have been ordered.

The Editorial Board invite special articles or editorials from expert authors from time to time, and supplements or special editions on a particular subject or theme of major importance are published when appropriate (such issues have included coverage of items at the ILA Congress and special issues to honour a particular person or event).

\section{Peer review}

The name(s) of the author(s) and the place where the work was done has to be indicated clearly below the title of the manuscript, all of which are submitted for peer review by at least two referees with a specialisation in the field of the paper. Opportunity is also given for readership feedback on printed manuscripts via the Letters to the Editor pages and all authors are given a chance to respond to any such comment. Proofs are submitted to authors for immediate return by air.

\section{Circulation}

Leprosy Review is despatched to 1687 subscribers in 110 countries from all continents throughout the world and is published quarterly in March, June, September and December of each year. 931 issues are sent out free of charge to centres unable to provide the foreign currency to pay for it, 756 are paid for either by individuals, institutions or covered by ILEP grants. The majority of issues go to India (358), Brazil (58) and Nigeria (54) and the cost has remained at $£ 30$ since 1990 , heavily subsidized by LEPRA to ensure that this vital information reaches those least able to pay for it. Circulation reached a low of 1480 in 1994 but rallied well after that and since the new Editor has been in place has increased by over 200 .

\section{Finances}

The total cost of production and distribution of the Journal in 1997 was $£ 32,097$ ( $\$ 51,355$ by 
the exchange rate on 30.11.98)* This can be broken down:

$\begin{array}{lrr}\text { Printing } & £ 16,976 & (\$ 27,162) \\ \text { Despatch } & £ 9,767 & (\$ 15,627) \\ \text { Editorial Office } & £ 5,353 & (\$ 8,566)\end{array}$

* IJL costs are given as $\$ 126,706=£ 79,191$

Printing and postage costs are subject to variations due to price increases in paper and services, although the best possible rates are worked out with the printers and despatch house. Despite the increased circulation and quality of the Journal there are still only three people involved in its production and distribution. The Editor is unpaid, the Assistant Editor receives an hourly rate for work done on the Journal, and the Editorial Assistant is an employee of LEPRA.

\section{Future developments}

Following the great success of the first two series of posters, another set will be published, and further topics will be considered in the future.

Summaries of original papers, Contents, Editor's Choice, the Editorial and summaries of original articles from each issue are available on LEPRA's website (http://www.lepra.org.uk)

In a climate where one of the first things to go in an Institution's cash-strapped budget is a Journal, LEPRA is striving to ensure that all those who wish to have the Journal should have it without being penalized for lack of funds. Therefore it will continue its stated policy of providing '. . . free copies to doctors working with leprosy who are unable to afford the above subscription, and to selected libraries covering tropical medicine'. 